\title{
Prevalence of first permanent molar caries and streptococcusmutans \& lactobacillus level among 6- 7 year old School Children in Qassim province Kingdom of Saudi Arabia
}

\author{
Abdulmajeed Abdulrahman Aljabri,, ${ }^{1,}$ Anas Yousef Alammar², Khalifah Al Marshud ${ }^{3}$ \\ ${ }^{1,2,3}$ College of Dentistry, Qassim University Zulfi, Saudi Arabia \\ *Corresponding Author: \\ Email: abdulmajeed.aljabr@qudent.org
}

\begin{abstract}
Introduction: Dental caries is a bacterial disease of the calcified tissues of the teeth characterized by demineralization of the inorganic portion and destruction of the organic substance of the tooth and the first permanent molar the first victim of getting carious due to its early involvement. Caries has been known that is caused by bacteria fermenting food, producing acids and dissolving tooth mineral.

Objective: The first permanent molars are extremely influential dental structures in maxillofacial growth and development, and in the oral health status.

Aim: to assess the Prevalence of First Permanent Molar Caries Among 7-year old Children in Al-Qassim Province and its possible relation to the different levels of S. mutans (SM)and Lactobacilli (LB), salivary buffer capacity and salivary Ph.

Material \& Methods: a cross sectional analytical study design. With a total of 243 children, aged 6-7 year old selected from different schools randomly. Clinical examination of children was conducted to assess dental caries, and saliva was collected to assess S. mutans levels, lactobacilli, salivary PH, and buffering capacity of saliva. Results: Prevalence of carious first permanent molars was high $153(63 \%)$. No statistically significant difference revealed by chi-square test between carious first permanent molars and Ph. A statistical significant difference was found between carious first permanent molars and saliva buffer capacity. Must patients had high buffer capacity. Chi-square test revealed that the relation between caries and SM levels was highly statistically significant at $\mathrm{P}<0.001$ same thing was found in relation with LB. Children with carious first permanent molars tend to have a higher number of SM and LB in saliva than children with sound first permanent molars.

Conclusion: The Prevalence of First Permanent Molar Caries Among 7-year old Children in Al-Qassim Province is high. Levels of SM and LB were also higher; this result gives an indication that there is a higher risk for those children to develop more caries in their permanent teeth in the future. Moreover, it emphasizes the importance of early intervention and educational programs, which should be implemented even before the FPMs erupt (4- to 5-year-old children).
\end{abstract}

Keywords: DentalCaries, First permanent molar, Lactobacilli, Streptococcus mutans, salivary buffering capacity and Salivary PH.

\section{Introduction}

Dental caries is a bacterial disease of the calcified tissues of the teeth characterized by demineralization of the inorganic portion and destruction of the organic substance of the tooth. It is one of the main oral health problems in both industrialized and developing countries, and it affects $60-90 \%$ of school-going children. ${ }^{(1)}$ The prevalence of dental caries varies from $33.7 \%$ to $90 \%$ in the child population and is increasing at a worrisome rate. ${ }^{(2)}$ Several studies reported that dental caries levels might have risen dramatically among Saudi children during the past years. ${ }^{(3,4)}$ The first permanent molar, which might be called the first victim due to its early involvement, forms the key to occlusion and its early loss due to caries can have a significant impact on the future dental health of the child. Studies have shown high frequency of occlusal caries on the first permanent molar for all age groups, concluding that the occlusal surface of first permanent molar remains the most common site for caries within a short period following its eruption. ${ }^{(5-7)}$

At least two major groups of bacteria, namely the mutans streptococci (MS) and Lacto- bacilli (LB), are able to produce organic acids during metabolism of fermentable carbohydrates. ${ }^{(7,8)}$ The studies have shown that the subjects with active caries tend to harbor a higher number of mutans streptococci and lactobacilli in their saliva than those who are caries free. ${ }^{(8,9)}$ People with high counts of these potentially cariogenic bacteria are considered to be 'at-risk', and can be targeted for intensive oral hygiene, antimicrobial therapy and dietary counseling. Many attempts have been made recently to identify those children who are more susceptible to caries development to implement specific prevention programs for them. Aim: Aim was to assess the Prevalence of First Permanent Molar Caries Among 7-year old Children in Al-Qassim Province and its possible relation with the different levels of S. mutans (SM) \& Lactobacilli (LB), salivary buffer capacity and salivary $\mathrm{Ph}$.

\section{Materials and Methods}

A cross-sectional analytical study design was used to determine the prevalence of dental caries in the FPMs. A total of 243 school children was examined from randomly selected primary school grade one. Three private \&five public schools were selected in Qassim region.

Necessary permission was taken from school authorities and the written informed consent was taken from the parents before the start of the study.

\section{Inclusion criteria:}


- Children who were permanent residents of $\mathrm{Al}$ Qassim.

- Children with informed consent from parents.

Exclusion criteria:

- Children with systemic disease.

- Children who were severely ill.

- Children having difficulty in opening the mouth.

- Children who have taken antibiotics in the last month.

- Children with orthodontic appliances..$^{(10)}$

The study was carried out using a specific sequence, which consisted of:

Oral Hygiene Questionnaire: Questionnaires about oral habits, and oral hygiene were distributed to the children to examine their knowledge about the importance of oral hygiene.(Fig. 1)

Dental Examination: Examination of teeth was carried out was carried out under natural light using a mouth mirror and dental explorer. Disposable sterilized instruments were used. No radiographs were used. The same examiner had examined all children.(Fig.2)

The teeth were dried using cotton rolls. Dental caries were measured using DMFS for primary and permanent teeth respectively, using the criteria of WHO. .11) $^{(1)}$

Procedures for assessing salivary samples for Streptococcusmutans, lactobacilli, salivary buffering capacity, and salivary PH level.

4 test were done, which are

1. Salivary PH (Fig. 4).

2. Salivary Buffering Capacity (Fig. 5).

3. Streptococcus Mutans level in saliva (Fig. 6).

4. Lactobacilli level in saliva (Fig. 7).

Method of saliva collection: Saliva collection was scheduled after the clinical examination. Students were examined one at a time. During saliva collection, students were asked to comfortably set on their chairs. Children were ask to swallow the preexisting saliva, in order to clear the mouth of any residual unstimulated saliva.

After this, each student was given a standard piece of paraffin wax and asked to chew it for $5 \mathrm{~min}$ and the stimulated saliva is collected in a sterilized container (Fig. 8).

The CRT bacteria caries risk test from Ivoclar Vivadent was used. It enables the simultaneous determination of the mutans streptococci and lactobacilli counts in saliva by means of selective agars. It contained two colored agars (Fig. 9). The blue ismitis-salivariusagar with bacitracin was used to detect mutans streptococci (Fig. 10), while the light culture medium, Rogosa agar, used to evaluate lactobacilli (Fig. 11).

The patients were asked to chew paraffin pellets in order to transfer the bacteria from the tooth surfaces in the saliva.

Saliva was then collected in a suitable container. $\mathrm{NaHCO} 3$ tablet* placed in the test vial releases $\mathrm{CO} 2 *$ when it comes into contact with moisture. This creates favorable conditions for bacterial growth. The agars were protected. Draught, sneezing, or coughing near the agars were avoided. Both agars, mitis-salivarius agar and Rogosa agar, were entirely covered with saliva using a pipette without scratching the culture media (Fig. 12).

Saliva was entirely covering the agars. Holding the carrier slightly oblique was done to prevent the saliva from flowing off too quickly and favors the thorough wetting of the surface (Fig. 12, 13). The agar carriers were immediately placed in the test vials, which are tightly sealed (Fig. 14, 15). Two days of incubation in an incubator at $37^{\circ} \mathrm{C} / 99^{\circ} \mathrm{F}$ were sufficient to allow the bacterial colonies to grow.

S.mutans occurred as small blue colonies with a diameter of $<1 \mathrm{~mm}$ on the blue agar, while Lactobacilli were detected as white colonies on the transparent agar.

The comparison with the corresponding pictures in the model chart permitted the assessment of the caries risk. Counting the colonies was done after the agars were taken out from the incubator. Counts higher than $10^{\wedge} 5 \mathrm{CFU}$ of S.mutans and/ or Lactobacillus per milliliter of saliva indicating a high/lower risk for dental caries, ${ }^{(7)}$ were recorded.

*Remark:

$\mathrm{NaHCO} 3=$ sodium hydrogen carbonate.

$\mathrm{CO} 2$ = carbon dioxide.

Buffering capacity of saliva: CRT buffer was used to determine the buffer capacity of saliva by means of a test strip featuring a special indicator system.

Each patient was asked to chew a paraffin pellet for 5 minutes to stimulate salivation(Fig. 8). Then saliva is collected in a calibrated container. The collected saliva is dropped off on a special test field with Pipet. The test strips are left wet with saliva for 5 minutes. Then buffer capacity is determined by comparing the color of the test strips with the chart given by the company.(Fig. 16, 17)

Salivary PH determination: $\mathrm{PH}$ was tested using $\mathrm{PH}$ test strips (fig.4) from Maximum Wellbeing by immersing the test strip in a saliva container. The strips are left for 15 second. The $\mathrm{PH}$ is then measured by comparing the color of the strip with that chart given by the company (Fig. 4, 17).

Statistical analysis: The Statistical Package for Social Science (SPSS), version 20, was used for analysis.

\section{Results}

Caries prevalence: A total of 243 patients 144 (59.3\%) patients was diagnosed with carious lower molars. While $99(40.7 \%)$ had sound lower molars (Table 1). Similar results were found for the upper molars $135(55.6 \%)$ of the patients had caries in their upper first molars. In addition, 108 (44.4\%) had sound upper molars (Table 2).

Moreover, $108(44.4 \%)$ had sound upper molars (Table 2). Generally, 153 (63\%) patient had caries in 
either upper or lower first permanent molars or both. 90(37\%) patients had sound upper and lower first permanent molars (Table 3).

Salivary PH level: There was no statistically significant difference between caries and salivary PH in this study.

216 of the total children had normal salivary $\mathrm{pH}$ level. Out of those, $81(37.5 \%)$ of them had sound teeth while $135(62.5 \%)$ with carious teeth. On the other hand, out of 27 patients9 $(33.3 \%)$ with sound teeth and $18(66.7 \%)$ with carious teeth an acidic $\mathrm{pH}$ (Table 4$)$.

Salivary buffering capacity: High statistically significant difference was found between carious first permanent molars and sound first permanent molars in relation to saliva buffer capacity using chi-square test at $\mathrm{P}<0.001$. Most children had high buffer capacity. In a total of 90 children with sound teeth, 27, 27, 36 were the number of children found with low, medium and high salivary buffer capacity respectively. In reverse to that, 27, 18, 107 were the number of children with low, medium and high salivary buffer capacity respectively (Table 5).

S. mutans in Saliva: The relation between caries and SM levels was highly statistically significant.
153Children were diagnosed with SM level more than $10^{\wedge} 5,36(23 \%)$ of them were found with no carious permanent teeth, while $117(76.5 \%)$ of those children were having caries. In reverse, results of SM levels were less than $10^{\wedge} 5$ on 90 patients, 54(60\%) of them had sound permanent first molars and $36(40 \%)$ had carious permanent first molars (Table 6).

Lactobacillus level in Saliva All patients found with high level of SM had high levels of LB. results of LB in saliva are the same as that found in SM. The relation between caries and LB levels was highly statistically significant.

Relation between First permanent molars and dmft: The difference between sound and carious Permanent molars and $\mathrm{dmft}^{*}$ was highly statistically significant at $\mathrm{P}<0.05$. The mean of $\mathrm{dmft}$ for the carious first permanent molars was 9.47, which means that for patients with carious permanent molars, the $\mathrm{dmft}$ was high with a mean 9.47. On the other hand, the mean of $\mathrm{dmft}$ for children with sound permanent molars was 5.10.

*decade, missed due to caries and filled primary teeth.

There is more susceptibility for first permanent molars to be curious if $\mathrm{dmft}$ is high (Table 7).

Table 1: Frequency of carious lower first permanent molars

\begin{tabular}{|c|l|c|c|c|c|}
\hline \multicolumn{6}{|c|}{ Carious Lower First Permanent Molars } \\
\hline \multicolumn{2}{|c|}{} & Frequency & Percent & $\begin{array}{c}\text { Valid } \\
\text { Percent }\end{array}$ & $\begin{array}{c}\text { Cumulative } \\
\text { Percent }\end{array}$ \\
\hline \multirow{2}{*}{ Valid } & Sound & 99 & 40.7 & 40.7 & 40.7 \\
\cline { 2 - 6 } & Carious & 144 & 59.3 & 59.3 & 100.0 \\
\cline { 2 - 6 } & Total & 243 & 100.0 & 100.0 & \\
\hline
\end{tabular}

Table 2: Frequency of carious upper first permanent molars

\begin{tabular}{|l|l|c|c|c|c|}
\hline \multicolumn{7}{|c|}{ Carious Upper First Permanent Molars } \\
\hline \multicolumn{2}{|c|}{} & Frequency & Percent & $\begin{array}{c}\text { Valid } \\
\text { Percent }\end{array}$ & $\begin{array}{c}\text { Cumulative } \\
\text { Percent }\end{array}$ \\
\hline \multirow{2}{*}{ Valid } & Sound & 108 & 44.4 & 44.4 & 44.4 \\
\cline { 2 - 6 } & Carious & 135 & 55.6 & 55.6 & 100.0 \\
\cline { 2 - 6 } & Total & 243 & 100.0 & 100.0 & \\
\hline
\end{tabular}

Table 3: Frequency of carious first permanent molars

\begin{tabular}{|l|l|c|c|c|c|}
\hline \multicolumn{7}{|c|}{ Carious First Permanent Molars } \\
\hline \multicolumn{2}{|c|}{} & Frequency & Percent & $\begin{array}{c}\text { Valid } \\
\text { Percent }\end{array}$ & $\begin{array}{c}\text { Cumulative } \\
\text { Percent }\end{array}$ \\
\hline \multirow{3}{*}{ Valid } & .00 & 90 & 37.0 & 37.0 & 37.0 \\
\cline { 2 - 6 } & 1.00 & 153 & 63.0 & 63.0 & 100.0 \\
\cline { 2 - 6 } & Total & 243 & 100.0 & 100.0 & \\
\hline
\end{tabular}

Table 4: Relation between first permanent molar caries and salivary Ph

\begin{tabular}{|c|c|c|c|c|c|}
\hline \multicolumn{6}{|c|}{ Crosstab } \\
\hline & & & \multicolumn{2}{|c|}{ PH_QL } & \multirow[t]{2}{*}{ Total } \\
\hline & & & Normal & Acidic & \\
\hline \multirow[t]{4}{*}{ Caries } & \multirow[t]{2}{*}{.00} & Count & 81 & 9 & 90 \\
\hline & & $\%$ within $\mathrm{PH} \_\mathrm{QL}$ & $37.5 \%$ & $33.3 \%$ & $37.0 \%$ \\
\hline & \multirow[t]{2}{*}{1.00} & Count & 135 & 18 & 153 \\
\hline & & $\%$ within $\mathrm{PH} \_\mathrm{QL}$ & $62.5 \%$ & $66.7 \%$ & $63.0 \%$ \\
\hline
\end{tabular}




\begin{tabular}{|l|l|c|c|c|}
\hline \multirow{2}{*}{ Total } & Count & 216 & 27 & 243 \\
\cline { 2 - 5 } & $\%$ within PH_QL & $100.0 \%$ & $100.0 \%$ & $100.0 \%$ \\
\hline
\end{tabular}

\begin{tabular}{|l|c|c|c|c|c|}
\hline \multicolumn{7}{|c|}{ Chi-Square Tests } \\
\hline & Value & Df & $\begin{array}{c}\text { Asymp. Sig. } \\
\text { (2-sided) }\end{array}$ & $\begin{array}{c}\text { Exact Sig. } \\
\text { (2-sided) }\end{array}$ & $\begin{array}{c}\text { Exact Sig. } \\
\text { (1-sided) }\end{array}$ \\
\hline Pearson Chi-Square & $.179^{\mathrm{a}}$ & 1 & .673 & & \\
\hline
\end{tabular}

Table 5: Relation between first permanent molar caries and saliva buffer capacity

\begin{tabular}{|c|c|c|c|c|c|c|c|}
\hline \multicolumn{7}{|c|}{ Caries * Saliva buffer Cross tabulation } & \multirow[t]{3}{*}{$\mathbf{P}$} \\
\hline & & & \multicolumn{3}{|c|}{ Saliva buffer } & \multirow[t]{2}{*}{ Total } & \\
\hline & & & Low & Medium & High & & \\
\hline \multirow[t]{4}{*}{ Caries } & \multirow[t]{2}{*}{ Sound } & Count & 27 & 27 & 36 & 90 & \multirow[t]{6}{*}{$\mathrm{P}<0.001 *$} \\
\hline & & $\begin{array}{l}\text { \% within } \\
\text { Saliva buffer }\end{array}$ & $50.0 \%$ & $60.0 \%$ & $25.0 \%$ & $37.0 \%$ & \\
\hline & \multirow[t]{2}{*}{ Carious } & Count & 27 & 18 & 108 & 153 & \\
\hline & & $\begin{array}{l}\% \text { within } \\
\text { Saliva buffer }\end{array}$ & $50.0 \%$ & $40.0 \%$ & $75.0 \%$ & $63.0 \%$ & \\
\hline \multirow{2}{*}{\multicolumn{2}{|c|}{ Total }} & Count & 54 & 45 & 144 & 243 & \\
\hline & & $\begin{array}{l}\% \text { within } \\
\text { Saliva buffer }\end{array}$ & $100.0 \%$ & $100.0 \%$ & $100.0 \%$ & $100.0 \%$ & \\
\hline
\end{tabular}

Table 6: Relation between caries and SM \& LB

\begin{tabular}{|c|c|c|c|c|c|c|}
\hline \multicolumn{7}{|c|}{ Crosstab } \\
\hline & & & & \multicolumn{2}{|c|}{ SM } & \multirow[t]{2}{*}{ Total } \\
\hline & & & & $\begin{array}{l}\text { More Than } \\
10^{\wedge} 5\end{array}$ & Less than $10^{\wedge} 5$ & \\
\hline \multirow[t]{4}{*}{ Caries } & \multirow[t]{2}{*}{.00} & Count & & 36 & 54 & 90 \\
\hline & & $\%$ within SM & & $23.5 \%$ & $60.0 \%$ & $37.0 \%$ \\
\hline & \multirow[t]{2}{*}{1.00} & Count & & 117 & 36 & 153 \\
\hline & & \% within SM & & $76.5 \%$ & $40.0 \%$ & $63.0 \%$ \\
\hline \multirow{2}{*}{\multicolumn{2}{|c|}{ Total }} & Count & & 153 & 90 & 243 \\
\hline & & $\%$ within SM & & $100.0 \%$ & $100.0 \%$ & $100.0 \%$ \\
\hline \multicolumn{7}{|c|}{ Chi-Square Tests } \\
\hline \multicolumn{3}{|c|}{\begin{tabular}{l|l|} 
& Value \\
\end{tabular}} & Df & $\begin{array}{r}\text { Asymp. Si } \\
\text { (2-sided) }\end{array}$ & $\begin{array}{l}\text { Exact Sig. } \\
\text { (2-sided) }\end{array}$ & $\begin{array}{l}\text { Exact Sig. (1- } \\
\text { sided) }\end{array}$ \\
\hline \multicolumn{2}{|c|}{ Pearson Chi-Square } & $32.322^{\mathrm{a}}$ & 1 & .000 & & \\
\hline
\end{tabular}

T-Test Deciduous Vs. Permeant

Table 7: Relation between caries of first permanent molars and $\mathrm{dmft}$

\begin{tabular}{|c|c|c|c|c|c|c|}
\hline \multicolumn{6}{|c|}{ Group Statistics } & \multirow{2}{*}{$\begin{array}{c}\text { t-test } \\
\text { p }\end{array}$} \\
\hline & Caries & $\mathbf{N}$ & Mean & $\begin{array}{c}\text { Std. } \\
\text { Deviation }\end{array}$ & $\begin{array}{c}\text { Std. Error } \\
\text { Mean }\end{array}$ & \\
\hline \multirow[t]{2}{*}{ Dmft } & 1.00 & 153 & 9.47 & 4.174 & .337 & $\mathrm{P}<0.001$ \\
\hline & .00 & 90 & 5.10 & 3.226 & .340 & \\
\hline
\end{tabular}

*: statistically significant at $\mathrm{p}<0.005$

\section{Discussion}

Caries prevalence: As in our findings, the prevalence of carious first permanent molars was high (63\%) for children aged 6-7. It is similar in Qassim to some other regions in Saudi Arabia. Comparing the findings of a study done in Jeddah, Saudi Arabia for primary school children, they found that with 9 years old children the prevalence of carious first molars was $67 \%$ of the 9 -year- old children. They also found that as the age increases, the prevalence of caries increase. ${ }^{(12,13)}$

Another study, done in Qassim out of a sample of 3000 children $80.7 \%$ had caries in their first permanent molars. ${ }^{(13)}$

Cariogenic Bacteria (SM and LB): Relation between SM, and LB were highly statistically significant. All patients found with high level of SM had a high level of 
LB. and our findings were coexistent with other studies. ${ }^{(14)}$

There was highly statistically significant difference between caries and SM, and LB levels. SM and LB play important roles in the development and progression of dental caries. These bacteria are found in carious teeth in high levels in our study. Same results were found in other studies. ${ }^{(14-17)}$

Salivary PH: There was no statistically significant difference between caries and PH in this study; this may be because the sample that was selected for the test had not eaten anything for one hour.

Salivary Buffer capacity: The salivary buffering capacity had statistically significant correlation with the number of caries teeth. It is conceivable that salivary buffering capacity depends on the acidogenicity of bacteria; including MS. Salivary buffering capacity prevents a reduction in $\mathrm{pH}$ by neutralizing acid in the oral cavity after sugar intake.

High buffer capacity was found in the majority of the collected sample. Same results were found in a study done in Riga in 2008 for children aged 6 years. ${ }^{(14)}$

As most children had neutral $\mathrm{PH}$ values, it was suspected to have high buffer capacity even with carious permanent molars. ${ }^{(18)}$

Saliva buffer capacity gives more information if detected in different $\mathrm{pH}$ values as it changes and decreases with lower $\mathrm{pH}$ values, and increases when $\mathrm{pH}$ Value is high. ${ }^{(19)}$

\section{Conclusion}

The prevalence of caries in Qassim region is high.

Levels of SM and LB were high; this result gives an indication that there is a higher risk for this group of children to develop more caries in their permanent teeth in the future, which emphasize the importance of early intervention, and educational programs, which should be implemented even before the FPMs erupt (4- to 5-yearold children).

\section{Acknowledgment}

The Authors are grateful to Dr. Ramy Al Moazen for his valuable assistance in statistical analysis. They are also very thankful for the college of dentistry Scientific Research Center for funding us to buy the CRT bacteria test from Ivoclar Vivadent. And thanks the photographer Mohammed Alaqil, who spent a lot of time taking Photographs during the clinical trial.

\section{References}

1. Petersen PE, Bourgeois D, Ogawa H, Estupinan-Day S, Ndiaye C. The global burden of oral diseases and risks to oral health. Bull World Health Organ 2005;83:661-9.

2. Hegde PP, Ashok Kumar BR, Ankola VA Dental caries experience and salivary levels of streptococcus mutans and lactobacilli in 13-15 years old children of Belgaum city Karnaktaka. J Indian Soc Pedod Prev Dent 2005;23:23-6.

3. Stewart B, Al-Juhani T, Al-Akeel A. Caries experience in Grade 1 and 6 children attending elementary school at King
Abdulaziz Military City. Saudi Dental Journal. 2002;12:140-148.

4. Wyne A, Al-Ghorabi B, Al-Asir Y, Khan N. Caries prevalence in Saudi primary schoolchildren of Riyadh and their teachers' oral health knowledge, attitude and practices. Saudi Medical Journal. 2002;23(1):77-81.

5. Al-Shammery A, Guile E, El-Backly M. Prevalence of caries in primary school children in Saudi Arabia. Community Dentistry and Oral Epidemiology. 1990;18(6):320-321.

6. Featherstone JDB. Prevention and reversal of dental caries: role of low-level fluoride. Community Dent Oral Epidemiol 1999;27:31-40.

7. Berkowitz RJ. Acquisition and transmission of mutans streptococci. J Calif Dent Assoc 2003; 31:135-138

8. KR MRJ M. Dental caries: selected factors of children at risk. - PubMed - NCBI [Internet]. Ncbi.nlm.nih.gov. 1991,Jul-Aug;60(4):10-4. Available from: https://www.ncbi.nlm.nih.gov/pubmed/1936380.

9. D B, A A, A R. Associations between dietary intake, dental caries experience and salivary bacterial levels in 12-yearold English schoolchildren. - PubMed - NCBI [Internet]. Ncbi.nlm.nih.gov. 1996, Mar; 41(3):271-80. Available from: https://www.ncbi.nlm.nih.gov/pubmed/8735013.

10. Sakeenabi B Hiremath S. Dental caries experience and salivary Streptococcus mutans, Lactobacilli scores, salivary flow rate and salivary buffering capacity among 6-year-old Indian schoolchildren. Journal of Clinical and Experimental Dentistry. 2011;1(2):e412-e417.

11. Oral health surveys. 5th ed. Geneva: World Health Organization; 2013.

12. Al-Samadani K Ahmad M. Prevalence of First Permanent Molar Caries in and Its Relationship to the Dental Knowledge of 9-12-Year Olds from Jeddah, Kingdom of Saudi Arabia [Internet]. Ncbi.nlm.nih.gov. 2012,Mar 11. Available https://www.ncbi.nlm.nih.gov/pubmed/22461990.

13. Salem W.S., Araby Y.A. Significant Caries index in 1214 years old children in Qassim Area- Kingdom of Saudi Arabia. International Invention Journal of Medicine and Medical Sciences. 2015;2(1):12-16.

14. Nishikawara F, Katsumura S, Ando A, Tamaki Y, Nakamura Y, Sato $\mathrm{K}$ et al. Correlation of cariogenic bacteria and dental caries in adults. Journal of Oral Science. 2006;48(4):245-251.

15. Seibert W, Farmer-Dixon C, Bolden T, Stewrt JH. Streptococcus mutans levels and caries prevalence in lowincome schoolchildren. J Tenn Dent Assoc 2002;82:19-22.

16. Scheutz F, Frydenberg M, Matee MI, Poulsen S. The effectof choosing different units of analysis when estimating risk of presence of dental caries in the primary dentition. Com-munity Dent Health 2003;20:27-33.

17. Koll-Klais P, Mandar R, Leibur E, Kjaeldgaard M. High levels of salivary lactobacilli in Estonian schoolchildren. Eur J Pediatric Dent 20045:107-9.

18. Gudkina J Brinkmane A. Caries experience in relation to oral hygiene, salivary cariogenic micro flora, and buffer capacity and secretion rate in 6-year olds and 12 year olds in Riga. Stomatologija, Baltic Dental and Maxillofacial Journal. 2008;10(2):76-80.

19. Maldupa I, Brinkmane A, Mihailova A. Comparative analysis of CRT Buffer, GC Saliva Check Buffer tests and laboratory titration to evaluate saliva buffering capacity. Stomatologija, Baltic Dental and Maxillofacial Journal. 2011; 13(2):55-61. 